Article

\title{
Pharmacokinetics of Schizandrin and Its Pharmaceutical Products Assessed Using a Validated LC-MS/MS Method
}

\author{
Chi-Lin Li ${ }^{1}$, Yung-Yi Cheng ${ }^{1}$ (D), Chen-Hsi Hsieh ${ }^{1,2,3, *}$ and Tung-Hu Tsai 1,4,5,6,* \\ 1 Institute of Traditional Medicine, School of Medicine, National Yang-Ming University, Taipei 112, Taiwan; \\ a2233525@gmail.com (C.-L.L.); vininecheng@gmail.com (Y.-Y.C.) \\ 2 Division of Radiation Oncology, Department of Radiology, Far Eastern Memorial Hospital, \\ Taipei 220, Taiwan \\ 3 Faculty of Medicine, School of Medicine, National Yang-Ming University, Taipei 112, Taiwan \\ 4 Graduate Institute of Acupuncture Science, China Medical University, Taichung 404, Taiwan \\ 5 School of Pharmacy, College of Pharmacy, Kaohsiung Medical University, Kaohsiung 807, Taiwan \\ 6 Department of Chemical Engineering, National United University, Miaoli 36063, Taiwan \\ * Correspondence: chenciab@gmail.com (C.-H.H.); thtsai@ym.edu.tw (T.-H.T.); \\ Tel.: +886-2-2826-7115 (T.-H.T.); Fax: +886-2-2822-5044 (T.-H.T.)
}

Received: 25 December 2017; Accepted: 12 January 2018; Published: 15 January 2018

\begin{abstract}
Schisandra chinensis has been used as an important component in various prescriptions in traditional Chinese medicine and, more recently, in Western-based medicine for its anti-hepatotoxic effect. The aim of this study was to develop a selective, rapid, and sensitive ultra-performance liquid chromatography-tandem mass spectrometry method for pharmacokinetic studies of schizandrin in rats. Liquid-liquid extraction was used for plasma sample preparation. A UHPLC reverse-phase C18e column $(100 \mathrm{~mm} \times 2.1 \mathrm{~mm}, 2 \mu \mathrm{m})$ coupled with a mobile phase of methanol-0.1\% formic acid (85:15, $v / v$ ) was used for sample separation. A triple quadrupole tandem mass spectrometer was used to detect the analytes in the selected reaction monitoring mode. The linear range of schizandrin in rat plasma was $5.0-1000 \mathrm{ng} / \mathrm{mL}\left(\mathrm{r}^{2}>0.999\right)$, with a lower limit of quantification of $5 \mathrm{ng} / \mathrm{mL}$. The method was validated with regard to accuracy, intra-day and inter-day precision, linearity, stability, recovery, and matrix effects in rat plasma, which were acceptable according to the biological method validation guidelines developed by the FDA. This method was successfully applied to a pharmacokinetic study after oral administration of $3 \mathrm{~g} / \mathrm{kg}$ and $10 \mathrm{~g} / \mathrm{kg}$ of Schisandra chinensis products, which yielded a maximum concentration of schizandrin of $0.08 \pm 0.07$ and $0.15 \pm 0.09 \mu \mathrm{g} / \mathrm{mL}$, respectively. A parallel study design was used to investigate the oral bioavailability of single compound of schizandrin and the herbal extract, the single compound of pure schizandrin $(10 \mathrm{mg} / \mathrm{kg}$, i.v.), pure schizandrin (10 mg/kg, p.o.), and the herbal extract of Schisandra chinensis ( $3 \mathrm{~g} / \mathrm{kg}$ and $10 \mathrm{~g} / \mathrm{kg}$, p.o.) were given individually. The dose of Schisandra chinensis $(3 \mathrm{~g} / \mathrm{kg}$ ) equivalent to schizandrin $(5.2 \mathrm{mg} / \mathrm{kg})$; the dose of Schisandra chinensis $(10 \mathrm{~g} / \mathrm{kg})$ equivalent to schizandrin $(17.3 \mathrm{mg} / \mathrm{kg})$. The result demonstrated that the oral bioavailability of schizandrin was approximately $15.56 \pm 10.47 \%$ in rats, however the oral bioavailability of herbal extract was higher than single compound. The method was successfully applied to the pharmacokinetic study of pure schizandrin after oral administration of its pharmaceutical industry products in rats.
\end{abstract}

Keywords: bioavailability; pharmacokinetics; liquid-liquid extraction method; ultra-performance liquid chromatography-tandem mass spectrometry; traditional Chinese medicine 


\section{Introduction}

In traditional Chinese medicine, Schisandra fruit (Chinese herbal name: Wu-Wei-Zi) is a frequently used drug. According to the species of origin, clinically used two kinds of Schisandra chinensis were Schisandra chinensis and Schisandra sphenanthera. The active ingredients of the two Schisandra fruits have been analyzed, and their efficacy is comparable. In China and Japan, Schisandra fruit is mainly used to treat liver toxicity [1,2], asthma [3-5], and diabetes [6] and as a sedative and tonic $[7,8]$. Schisandra fruits are rich in dibenzocyclooctadiene-derived material. Botanical studies have shown that dibenzocyclooctadiene is the natural form. The presence of lignans is extreme low [9]. The 18-carbon dibenzocyclooctadiene lignans from Schisandra fruit have anti-oxidant $[6,10,11]$, anti-hepatotoxic [12,13], and anti-lipid peroxidation [14] effects. It has been documented that the 18-carbon dibenzocyclooctadiene lignans have anti-human immunodeficiency virus effects $[15,16]$, whereas homolignans containing 19 carbons are cytotoxic [17,18].

Recently, many Chinese medical doctors in Taiwan have come to prefer to prescribe commercial pharmaceutical herbal products instead of traditional decoctions because commercial pharmaceutical herbal products are convenient for patients. These products when produced by a cGMP pharmaceutical factory would be monitored for pesticide residues, heavy metals, and the dry herbs' source, etc. However, because the manufacturing processes of the pharmaceuticals differ from factory to factory, the concentrations of active compounds may vary too. Therefore, it is important to determine the active compounds in each $S$. chinensis commercial pharmaceutical product.

Since the 1990s, much attention has been paid to the pharmacokinetics of schizandrin, considered the main active ingredient in S. chinensis, and several analytical methods have been used to analyze schizandrin in rats, including GC-MS [19-22], LC [23-26], TLC [9,27,28], LC-MS [29], high-speed counter current chromatography $[30,31]$ and liquid chromatography tandem mass spectrometry (LC-MS/MS) [32]. LC-MS/MS has been applied to analyze the herbal ingredients in shengmai injection [32]. However, these methods are mostly applied to analyze raw herbs and extracts of S. chinensis. Samples are very time-consuming to obtain, with complicated sample pretreatments, and the methods are not sufficiently sensitive for pharmacokinetic studies. Although there is a previous study regarding the pharmacokinetics of orally dosing $S$. chinensis, its results were limited to giving comprehensive instructions for administering this herb. Herein, by investigating a conscious, freely moving animal model, it should more similar to the reality. To the best of our knowledge, there is no analytical method for the quantification of schizandrin and its pharmaceutical products in biological samples.

In recent years, LC-MS has been a ubiquitous technology for analyzing biosamples because its high sensitivity enables one to extend the concentration detection range. The aim of this study was to develop a convenient, specific and sensitive LC-MS/MS method for determination of schizandrin and its pharmaceutical industry products in biological samples. The validation and application of this assay are illustrated for the quantitative analysis of schizandrin in biological samples after oral administration of $S$. chinensis pharmaceutical products to rats. To investigate the oral bioavailability of the single compound schizandrin and the herbal extract, a parallel study design was followed using pure schizandrin (10 mg/kg, i.v.), pure schizandrin $(10 \mathrm{mg} / \mathrm{kg}$, p.o. $)$, and S. chinensis $(3 \mathrm{~g} / \mathrm{kg}$ and $10 \mathrm{~g} / \mathrm{kg}$, p.o.). The $3 \mathrm{~g} / \mathrm{kg}$ dose of $S$. chinensis was equivalent to $5.2 \mathrm{mg} / \mathrm{kg}$ schizandrin and the $10 \mathrm{~g} / \mathrm{kg}$ dose of $S$. chinensis was equivalent to $17.3 \mathrm{mg} / \mathrm{kg}$ schizandrin.

\section{Results and Discussion}

\subsection{Optimization of UPLC-MS/MS Conditions}

To evaluate the mass spectral fragmentation patterns of schizandrin and to optimize the set of parameters used, a standard solution of schizandrin $(100 \mathrm{ng} / \mathrm{mL})$ was analyzed by direct injection in the spectrometer. In the analytical conditions, a full scan in the positive mode (scan range from $\mathrm{m} / z 100$ to 500) was used to identify the analyte. The precursor ions of schizandrin and methyl yellow (used as 
internal standard) were at $m / z 433.22[\mathrm{M}+\mathrm{H}]^{+}$and $m / z 226.12[\mathrm{M}+\mathrm{H}]^{+}$, and the main product ions were at $m / z 415.19$ and $m / z 76.91$, as shown in Figure 1 . The analytes were detected in the positive ionization mode by monitoring the precursor-product combination in MRM mode, which provided high selectivity and sensitivity for the quantification assay.

(A)

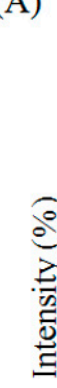

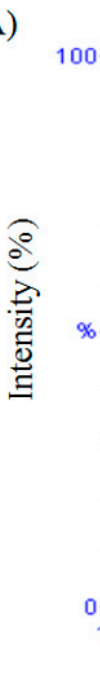

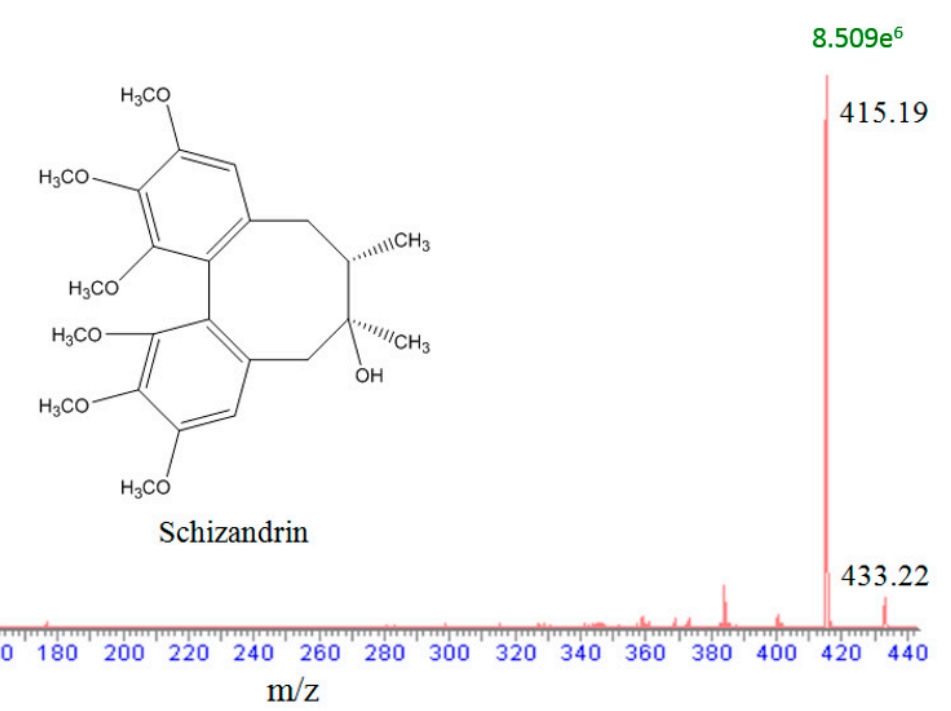

(B)

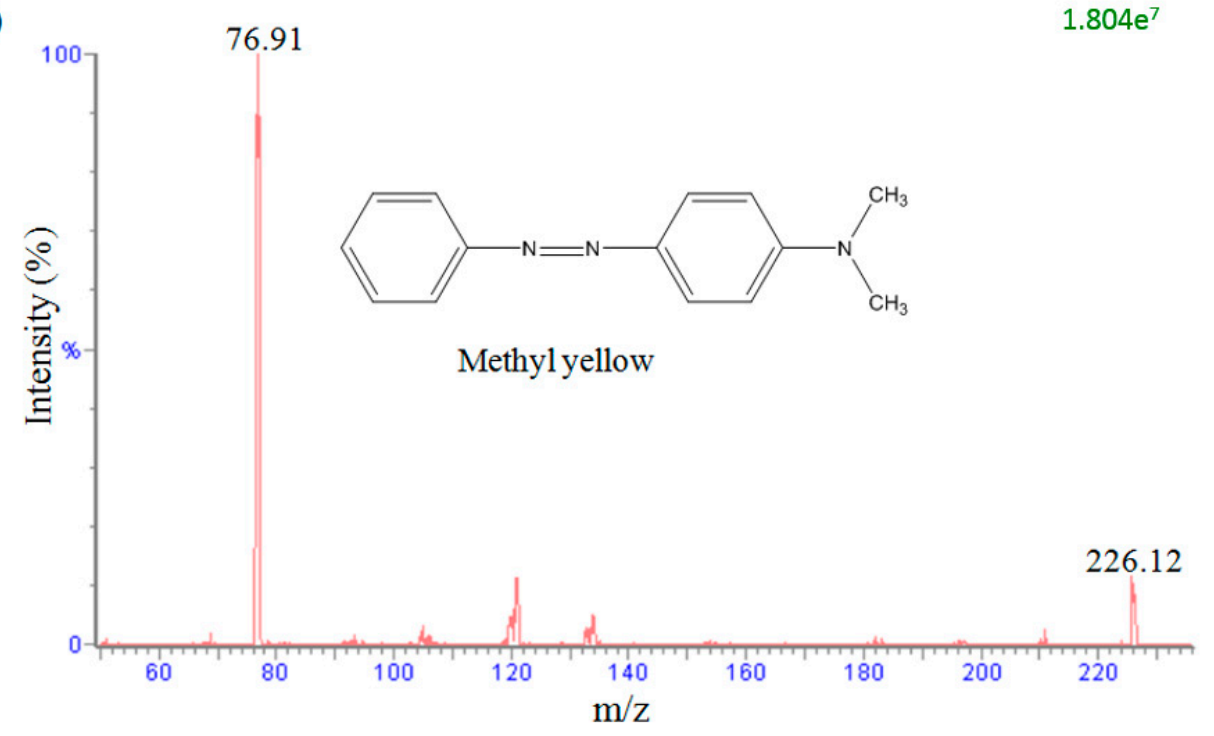

Figure 1. Representative product ion mass spectra and chemical structures of (A) schizandrin and (B) methyl yellow (internal standard).

In our study, the precursor ion of schizandrin at $m / z 433.22[\mathrm{M}+\mathrm{H}]^{+}$and its main product ion at $m / z 415.19$ were the same as those in a previous report [33]. After optimizing the assay conditions, the following experiments were performed to optimize the chromatographic separation of the analyte: chromatographic conditions, in particular the analytical column and the mobile phase composition (percentage of organic modifier, concentration and $\mathrm{pH}$ value of buffer), were optimized for good sensitivity and peak shape, as well as to achieve relatively short runs. It was observed that methanol produced a better peak shape than acetonitrile and was therefore selected as the organic phase. An improved peak shape was achieved by adding $0.1 \%$ formic acid to the mobile phase. Finally, a mobile phase consisting of a methanol- $0.1 \%$ formic acid solution was used in the experiment. Under optimized conditions, the reaction chromatogram of each analyte is shown in Figure 2. Figure 2A 
shows chromatograms of blank plasma after liquid-liquid extraction, demonstrating the baseline without any interference peaks in the chromatograms of real samples. Figure $2 \mathrm{~B}$ shows a chromatogram of a plasma sample spiked with schizandrin $(100 \mathrm{ng} / \mathrm{mL})$ and methyl yellow $(10 \mathrm{ng} / \mathrm{mL})$, and Figure $2 \mathrm{C}$ shows the real blood samples after schizandrin administration $(10 \mathrm{mg} / \mathrm{kg}$, i.v.) with methyl yellow (10 ng/mL).

(A)

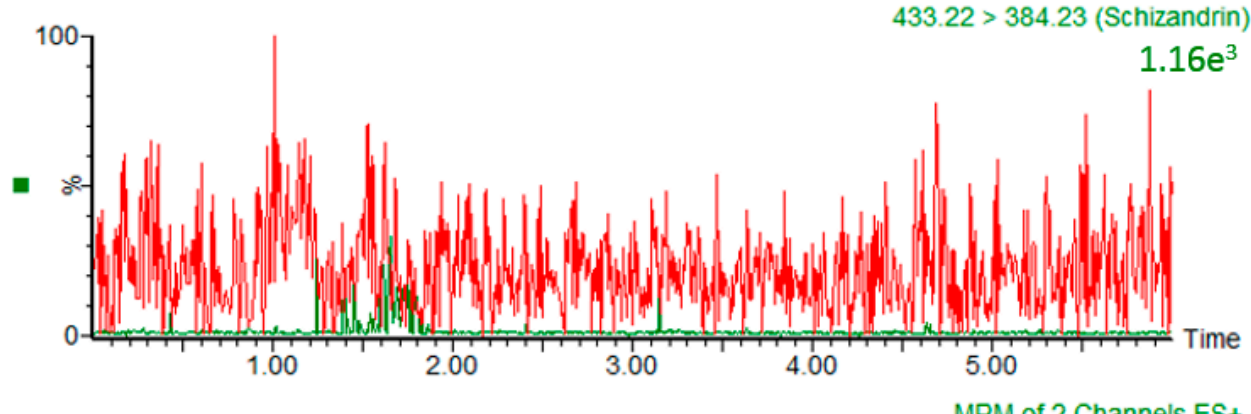
$1.16 \mathrm{e}^{3}$

(B)

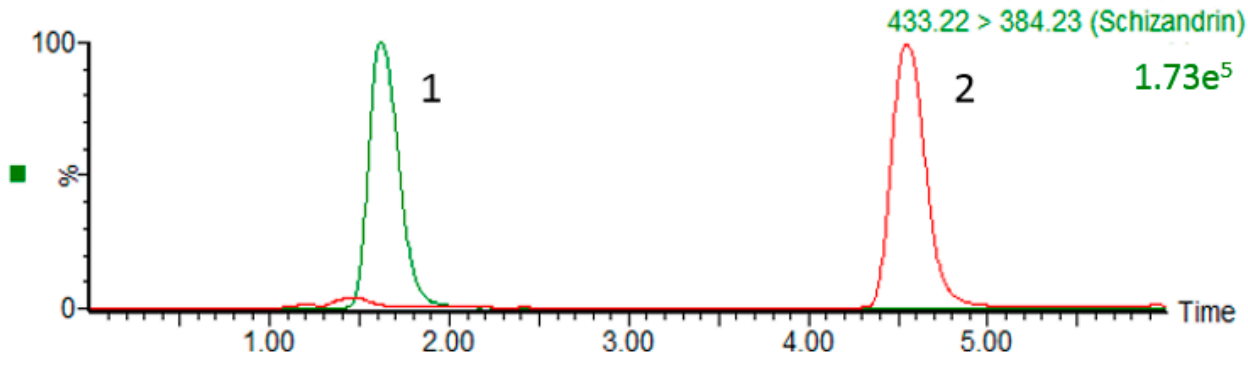

(C)

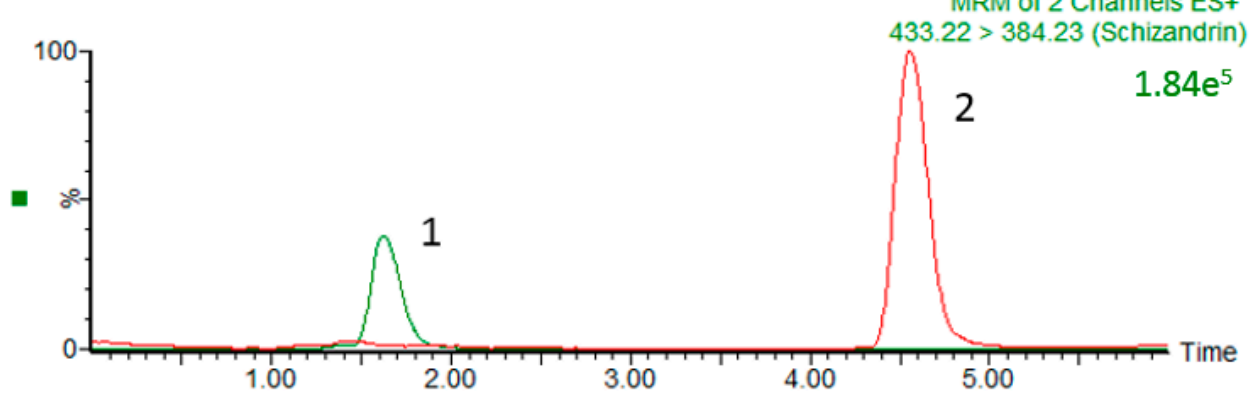

Figure 2. HPLC chromatograms (A) Blank plasma; (B) schizandrin standard (100 ng/mL) RT: $1.6 \mathrm{~min}$; and (C) plasma sample collected from the jugular vein of a rat at $15 \mathrm{~min}$ after schizandrin $(31.8 \mathrm{ng} / \mathrm{mL})$ administration (10 mg/kg, i.v.). 1: Schizandrin; 2: methyl yellow (internal standard).

\subsection{Method Validation}

Linear regression analysis of the calibration curve in blank plasma on six replicates per day over six different days indicate linearity between the nominal and the response concentration of schizandrin over the range of $5-500 \mathrm{ng} / \mathrm{mL}$. The correlation coefficient $\left(\mathrm{r}^{2}\right)$ was greater than 0.995 . The data showed excellent reproducibility. The limit of quantification (LOQ) and limit of detection (LOD) were defined as the concentration of schizandrin detected as a signal-to-noise $(\mathrm{S} / \mathrm{N})$ ratio of 10 and 3, respectively. The LOQ and LOD of schizandrin were 5 and $1 \mathrm{ng} / \mathrm{mL}$, respectively. The intra- and inter-day accuracy (\% bias) and precision (\% RSD) were determined at schizandrin concentrations of 5, 10, 50, 100, and $500 \mathrm{ng} / \mathrm{mL}$. The results of these analyses are presented in Table 1, and all the bias and RSD values were within $\pm 15 \%$, except for the LLOQ, which was within $\pm 20 \%$, although it was still within an acceptable range. These results indicated that the UPLC-MS/MS method is excellent for the quantitative analysis of schizandrin in biological samples. 
Table 1. Method validation for the intra-assay precision (\%RSD) and accuracy (\%Bias) of the HPLC method for the determination of schizandrin in plasma.

\begin{tabular}{cccc}
\hline $\begin{array}{c}\text { Nominal Concentration } \\
\text { (ng/mL) }\end{array}$ & $\begin{array}{c}\text { Observed Concentration } \\
\text { (ng/mL) }\end{array}$ & Precision RSD (\%) & Accuracy Bias (\%) \\
\hline Intra-assay & $5.01 \pm 0.12$ & 1.65 & \\
5 & $10.22 \pm 0.08$ & 2.83 & 0.19 \\
10 & $50.23 \pm 0.29$ & 0.67 & 0.45 \\
50 & $99.55 \pm 0.21$ & 0.21 & -0.45 \\
100 & $499.87 \pm 0.80$ & 0.16 & -0.03 \\
500 & & & \\
Inter-assay & $5.42 \pm 0.82$ & 15.16 & 8.40 \\
5 & $10.62 \pm 0.38$ & 3.55 & 6.20 \\
10 & $51.05 \pm 2.21$ & 4.33 & 2.10 \\
50 & $101.99 \pm 2.82$ & 2.76 & 0.99 \\
100 & $501.83 \pm 2.33$ & 0.46 & 0.37 \\
500 & & & \\
\hline
\end{tabular}

The data are presented as the mean \pm SD $(n=6)$. RSD: relative standard deviation. Observed concentration data are presented as the mean $\pm \mathrm{SD}$. Accuracy $(\%$ bias $)=\left[\left(\mathrm{C}_{\mathrm{obs}}-\mathrm{C}_{\text {nom }}\right) / \mathrm{C}_{\text {nom }}\right] \times 100$. Precision $(\% \mathrm{RSD})=\left[\mathrm{SD} / \mathrm{C}_{\mathrm{obs}}\right] \times 100$.

Three concentrations (low, medium, and high) were evaluated for recovery and matrix effects. The schizandrin concentrations detected were 5, 50, and $500 \mathrm{ng} / \mathrm{mL}$, and the methyl yellow concentration was $10 \mathrm{ng} / \mathrm{mL}$. The results indicated that the matrix effect and recovery of schizandrin in rat plasma were $91.5-97.8 \%$ and $90.8-99.6 \%$, respectively (Table 2). There were no significant differences in the analytical range, which was acceptable according to the FDA's biological method validation guidelines. The results indicated that this analytical method was acceptable for use in the pharmacokinetic study of schizandrin in freely moving rats.

Table 2. Recovery and matrix effect of schizandrin in rat plasma.

\begin{tabular}{|c|c|c|c|c|c|}
\hline \multirow{2}{*}{$\begin{array}{l}\text { Nominal Concentration } \\
(\mathrm{ng} / \mathrm{mL})\end{array}$} & \multicolumn{3}{|c|}{ Peak Areas } & \multirow{2}{*}{$\begin{array}{c}\text { Matrix Effect } \\
(\%)\end{array}$} & \multirow{2}{*}{ Recovery (\%) } \\
\hline & SET1 & SET2 & SET3 & & \\
\hline \multicolumn{6}{|l|}{ Schizandrin } \\
\hline 5 & $6862 \pm 268$ & $6279 \pm 682$ & $6118 \pm 403$ & $91.5 \pm 8.3$ & $97.4 \pm 5.8$ \\
\hline 50 & $72,483 \pm 1267$ & $70,910 \pm 3084$ & $70,723 \pm 7279$ & $97.8 \pm 2.8$ & $99.6 \pm 7.1$ \\
\hline 500 & $624,413 \pm 25,318$ & $572,304 \pm 50,936$ & $519,150 \pm 31,359$ & $91.6 \pm 4.3$ & $90.8 \pm 2.7$ \\
\hline Average & & & & $93.6 \pm 5.1$ & $96.1 \pm 5.2$ \\
\hline Methyl yellow & $62,710 \pm 2132$ & $72,097 \pm 2293$ & $67,947 \pm 2912$ & $115.0 \pm 4.0$ & $94.4 \pm 6.2$ \\
\hline
\end{tabular}

The stability of schizandrin is shown in Table 3. Three concentrations (low, medium, and high) were evaluated for stability. The schizandrin concentrations of 5,50, and $500 \mathrm{ng} / \mathrm{mL}$ were used in the method validation. The results demonstrated that schizandrin was stable under all the evaluated conditions. The schizandrin and IS stock solutions were found to be stable for up to 1 month at $-20^{\circ} \mathrm{C}$. No significant degradation of schizandrin occurred in biological samples after autosampler storage for $24 \mathrm{~h}$ at $10^{\circ} \mathrm{C}$, after short-term storage for $12 \mathrm{~h}$ at room temperature, after long-term storage for 1 month at $-80^{\circ} \mathrm{C}$, or after three freeze-thaw cycles at $-20^{\circ} \mathrm{C}$ and thawing at room temperature.

Table 3. The stability data for schizandrin in rat plasma.

\begin{tabular}{ccccc}
\hline $\begin{array}{c}\text { Blood Concentration } \\
(\mathbf{n g} / \mathbf{m L})\end{array}$ & $\begin{array}{c}\text { Short-Term } \\
\text { Stability }\end{array}$ & $\begin{array}{c}\text { Autosampler } \\
\text { Stability }\end{array}$ & $\begin{array}{c}\text { Freeze-Thaw } \\
\text { Stability }\end{array}$ & $\begin{array}{c}\text { Long-Term } \\
\text { Stability }\end{array}$ \\
\hline 5 & $-1.63 \pm 8.36$ & $-1.78 \pm 2.25$ & $-8.04 \pm 3.19$ & $-0.56 \pm 0.39$ \\
50 & $5.70 \pm 4.52$ & $3.17 \pm 3.19$ & $-5.16 \pm 3.83$ & $-9.02 \pm 0.40$ \\
500 & $0.64 \pm 0.08$ & $0.43 \pm 0.12$ & $-0.63 \pm 0.30$ & $-6.75 \pm 6.39$ \\
\hline
\end{tabular}

The data presented as the mean \pm SD. Short-term stability: kept at room temperature for $12 \mathrm{~h}$; Autosampler stability: kept at $10{ }^{\circ} \mathrm{C}$ for $24 \mathrm{~h}$ in autosampler; Freeze-thaw stability: three freeze-thaw cycles; Long-term stability: kept at $-20^{\circ} \mathrm{C}$ for 1 month. 


\subsection{Sample Preparation}

The sample preparation method was pretested and included a liquid-liquid extraction method (LLE) with ethyl acetate and protein precipitation with methanol [31]. Comparing the process efficiency of the LLE and protein precipitation, we found that protein precipitation had lower process efficiency due to the high polarity of schizandrin. Therefore, liquid-liquid extraction was selected as the sample preparation method in this study. The recovery (RE) and matrix effect (ME) were 90.8-99.6\% and 91.5-97.8\%, respectively. As shown in the above results, LLE with acidified ethyl acetate had a high efficiency with an acceptable RE and ME. In our study, LLE with acidified ethyl acetate was chosen as the sample preparation method.

\subsection{Pharmacokinetic Applications}

This developed and validated method was used to determine the plasma concentration of schizandrin in freely moving rats. Because the pharmaceutical industry Schisandra products contained starch as the excipient, it was difficult to use a high concentration for oral gavage. Based on the pharmaceutical analysis, an oral single dose of S. chinensis $(3 \mathrm{~g} / \mathrm{kg}$ and $10 \mathrm{~g} / \mathrm{kg}$ ) was determined for the pharmacokinetic study in rats with a volume of $10 \mathrm{~mL} / \mathrm{kg}$ [33]. The equivalent dosages of schizandrin of two oral S. chinensis product groups were $5.2 \mathrm{mg} / \mathrm{kg}$ for $3 \mathrm{~g} / \mathrm{kg}$ and $17.3 \mathrm{mg} / \mathrm{kg}$ for $10 \mathrm{~g} / \mathrm{kg}$, respectively. The concentration-time profiles of schizandrin after oral administration of schizandrin or S. chinensis are presented in Figure 3.

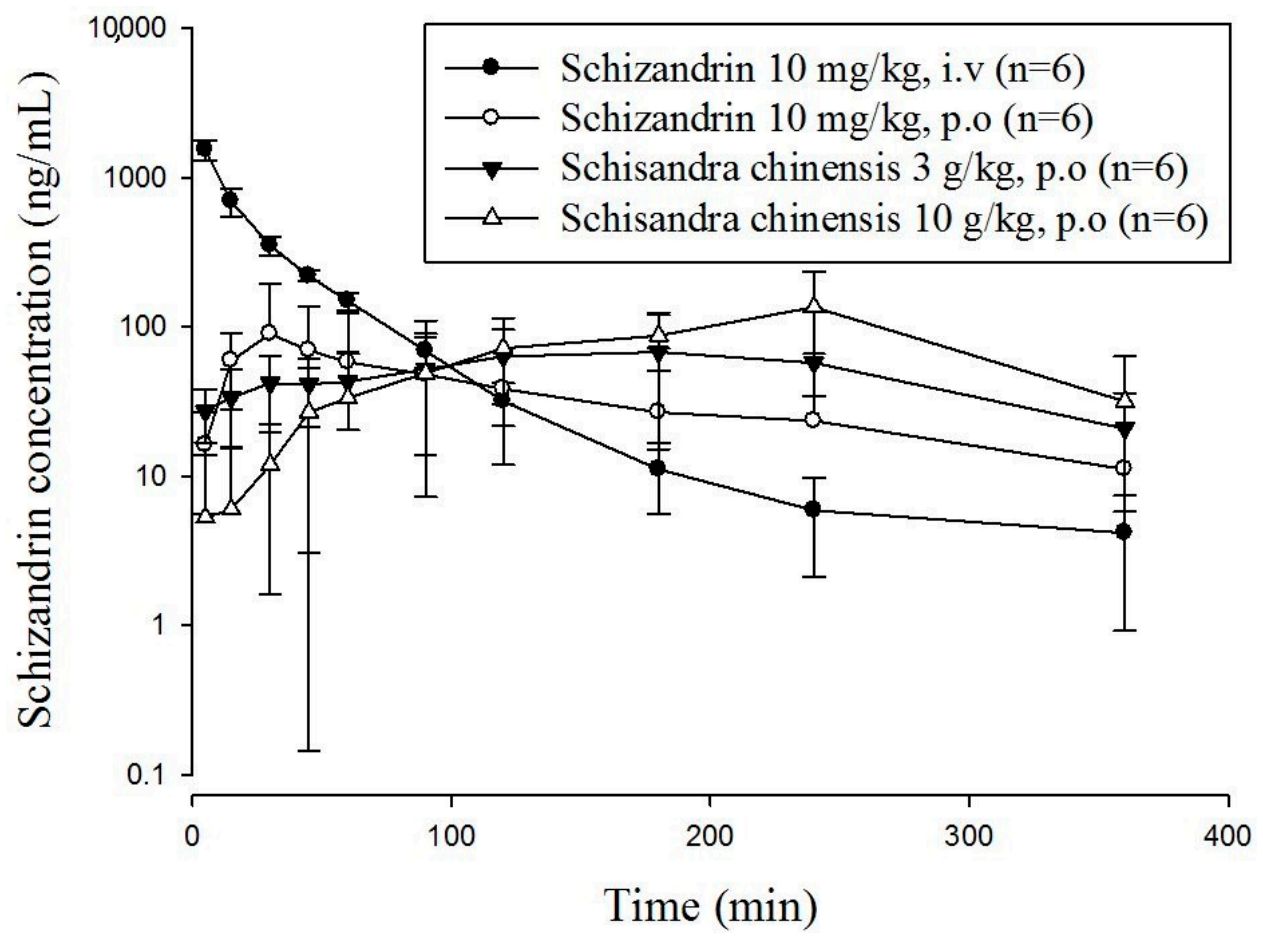

Figure 3. Concentration-time curve of schizandrin in rat plasma after intravenous $(10 \mathrm{mg} / \mathrm{kg}$, i.v. $)$ and oral administration of S. chinensis ( $3 \mathrm{~g} / \mathrm{kg}$ or $10 \mathrm{~g} / \mathrm{kg}$, p.o.) and schizandrin $(10 \mathrm{mg} / \mathrm{kg}$, p.o.); mean $\pm \mathrm{SD}, n=6$. The dose of $S$. chinensis $(3 \mathrm{~g} / \mathrm{kg})$ equivalent to schizandrin $(5.2 \mathrm{mg} / \mathrm{kg})$; the dose of S. chinensis $(10 \mathrm{~g} / \mathrm{kg})$ equivalent to schizandrin $(17.3 \mathrm{mg} / \mathrm{kg})$.

The pharmacokinetic parameters are summarized in Table 4. The time to reach the maximum peak plasma concentration of a drug after administration in biological systems can be used as an index of the drug absorption rate. In our research, in oral administration groups, the $\mathrm{T}_{\max }$ values range from 22 to $200 \mathrm{~min}$. The basic pharmacokinetic and bioavailability information for schizandrin were obtained from a single intravenous treatment at one dosage $(10 \mathrm{mg} / \mathrm{kg})$ and oral administration at 
three dosages $(10 \mathrm{mg} / \mathrm{kg}, 3 \mathrm{~g} / \mathrm{kg}$ and $10 \mathrm{~g} / \mathrm{kg})$ in rats. Pharmacokinetic parameters were calculated by the software program WinNonlin.

Table 4. Pharmacokinetic parameters of schizandrin in rat plasma.

\begin{tabular}{|c|c|c|c|c|}
\hline \multirow{2}{*}{ Parameter } & \multicolumn{2}{|c|}{ Schizandrin } & \multicolumn{2}{|c|}{ Schisandra chinensis } \\
\hline & $10 \mathrm{mg} / \mathrm{kg}$, i.v. & 10 mg/kg, p.o. & 3 g/kg, p.o. & 10 g/kg, p.o. \\
\hline$C_{\max }(\mu \mathrm{g} / \mathrm{mL})$ & & $0.06 \pm 0.03$ & $0.08 \pm 0.07$ & $0.15 \pm 0.09^{a}$ \\
\hline $\operatorname{AUC}(\min \mathrm{ng} / \mathrm{mL})$ & $43.11 \pm 5.62$ & $6.71 \pm 4.51$ & $17.58 \pm 12.31$ & $28.03 \pm 14.29^{a}$ \\
\hline $\mathrm{t}_{1 / 2}(\mathrm{~min})$ & $42.25 \pm 14.84$ & $74.69 \pm 33.56$ & $68.20 \pm 23.93$ & $51.97 \pm 12.35$ \\
\hline $\mathrm{T}_{\max }(\min )$ & & $22.50 \pm 12.55$ & $185.00 \pm 101.14^{a}$ & $200.00 \pm 45.17^{\mathrm{a}}$ \\
\hline $\mathrm{CL}(\mathrm{L} / \mathrm{min} / \mathrm{kg})$ & $0.24 \pm 0.03$ & $0.34 \pm 1.24$ & $0.33 \pm 0.24$ & $0.30 \pm 0.46$ \\
\hline MRT (min) & $34.80 \pm 7.53$ & $113.42 \pm 41.65$ & $206.07 \pm 41.97^{\mathrm{a}}$ & $213.63 \pm 32.00^{a}$ \\
\hline $\mathrm{F}(\%)$ & & $15.56 \pm 10.47$ & $78.42 \pm 54.91^{\mathrm{a}}$ & $37.59 \pm 19.16^{\mathrm{a}}$ \\
\hline
\end{tabular}

Data are presented as the mean $\pm \mathrm{SD}, n=6$. AUC: area under the concentration-time curve; CL: clearance; MRT: mean residence time; F, bioavailability. The dose of S. chinensis $(3 \mathrm{~g} / \mathrm{kg})$ equivalent to schizandrin $(5.2 \mathrm{mg} / \mathrm{kg})$; the dose of S. chinensis $(10 \mathrm{~g} / \mathrm{kg})$ equivalent to schizandrin $(17.3 \mathrm{mg} / \mathrm{kg}) .{ }^{\text {a }}$ Significantly different from oral ingestion schizandrin group at $p<0.05$.

Pharmacokinetic parameters for intravenous and oral administration were calculated by non-compartmental analysis, also called model independent analysis. The pharmacokinetic parameters of intravenous group revealed the half-life $\left(t_{1 / 2}\right)$, clearance $(C L)$, mean residence time (MRT), area under the concentration-time curve (AUC) and volume of distribution (Vd). The pharmacokinetic parameter for MRT was $34.80 \mathrm{~min}$, the CL was $0.09 \mathrm{~L} / \mathrm{min}$, and the AUC was $43.11 \mathrm{~min} \mathrm{ng} / \mathrm{mL}$, suggesting that the elimination process is rapid. The areas under the concentration-time curves (AUCs) of ingesting schizandrin group was $6.71 \pm 4.51$, and other two groups were $17.58 \pm 12.31$ and $28.03 \pm 14.29 \mathrm{~min} \mathrm{gg} / \mathrm{mL}$ for the dosages of $3 \mathrm{~g} / \mathrm{kg}$ and $10 \mathrm{~g} / \mathrm{kg}$ S. chinensis product, respectively.

Reviewing the profiles, up to $120 \mathrm{~min}$, the plasma concentrations of schizandrin resulting from the pharmaceutical industry $S$. chinensis products were significantly higher than the concentrations resulting from orally administering the pure compound schizandrin. The clearances (CL) of the three orally administered at the dosages of $10 \mathrm{mg} / \mathrm{kg}, 3 \mathrm{~g} / \mathrm{kg}$, and $10 \mathrm{~g} / \mathrm{kg}$ were $0.34 \pm 1.24,0.33 \pm 0.24$ and $0.30 \pm 0.46 \mathrm{~mL} / \mathrm{min} / \mathrm{kg}$, respectively. Although the $\mathrm{T}_{\max }$ and the MRT of orally given schizandrin group were shorter than that of S. chinensis $(p<0.05)$ groups, there were no significant differences in the clearances among the three groups. The short half-life, short mean residence time and high clearance rate of schizandrin imply that the elimination process might be rapid. Our findings indicated that the $\mathrm{T}_{\max }$ and MRT values of orally ingesting $S$. chinensis products are larger than that of the dosing single component schizandrin, which also matches Feary's study [34]. According to previous reports, narcotics have an impact on the outcomes of animal experiments [35]. Therefore, the results might be different from those of the previous studies. We determined the bioavailability and the degree and rate at which a drug is absorbed into a circulatory system. Bioavailability was calculated using the following formula:

$$
\mathrm{F}(\%)=100 \times\left(\mathrm{AUC}_{\text {oral }} / \mathrm{D}_{\text {oral }}\right) /\left(\mathrm{AUC}_{\mathrm{iv}} / \mathrm{D}_{\mathrm{iv}}\right) .
$$

In our study, we used the $\mathrm{AUC}_{\mathrm{iv}}$ value of schizandrin to calculate the bioavailability of schizandrin and S. chinensis ( $3 \mathrm{~g} / \mathrm{kg}$ and $10 \mathrm{~g} / \mathrm{kg}$ ). According to the data, the oral bioavailability of schizandrin was $15.56 \pm 10.47 \%$, and that of S. chinensis was $78.42 \pm 54.91 \%$ and $37.59 \pm 19.16 \%$. The schizandrin data is the same as those in the previous report [36]. Hepatic first-pass and intestinal effects are widely acknowledged to be responsible for the low oral bioavailability of schizandrin. Systematic elimination may also occur in the gastrointestinal wall. Due to robust first-pass metabolism, schizandrin could be metabolized rapidly, resulting in less schizandrin entering the circulation and therefore presenting low bioavailability at high doses. Thus, schizandrin displays nonlinear pharmacokinetics after oral administration due to nonlinear metabolism in the liver. According to the comparative pharmacokinetics results shown in Table 4, the $C_{\max }$ and $T_{\max }$ of pharmaceutical industry S. chinensis products were significantly different from that of single ingestion group. 
In Figure 3, the drug concentration of orally administering schizandrin reaches the $\mathrm{C}_{\max }$ within $30 \mathrm{~min}$, which was significantly faster and higher than those from given by $S$. chinensis product. This phenomenon may be due to the fact that pure compound schizandrin is a small molecule with a molecular weight less than 500 Da [37], which dissolves completely in water and did not form granules. Therefore, the absorption of pure compound schizandrin may be more efficient than its absorption from extracts containing mixtures of excipients. The schizandrin of the granulated pharmaceutical industry S. chinensis products were covered by excipients, which may release slowly and delay for absorption than pure compound. In addition, the other ingredients in S. chinensis, excipients in commercial pharmaceutical products, which usually contain starch for granulation, might affect the absorption of schizandrin. The schizandrin levels in the plasma of rats given the commercial pharmaceutical products showed a later $\mathrm{T}_{\max }$ and longer persistence than the levels in rats given the pure compound. This effect may be due to the starch solution being mushy and prolonging the gastric emptying time. Based on those phenomena, we concluded that the plasma concentration of schizandrin in rats given $S$. chinensis was detected for $6 \mathrm{~h}$, and the mean retention time was longer than that of the pure compound schizandrin, which might be because that schizandrin was reabsorbed into the blood and retained in the body. In this study, we first focused our investigation on the pharmacokinetic profile of major bioactive components in pharmaceutical products. The validated LC-MS/MS method was successfully applied to a pharmacokinetic study in freely moving rats after pure schizandrin and pharmaceutical products of S. chinensis. Finally, Traditional Chinese medicines have been used for thousands of years in Asia, and there is still a large amount of empirical information awaiting new scientific explanations. These studies provide constructive comparative pharmacokinetic information about single schizandrin and pharmaceutical industry products for clinical application

\section{Materials and Methods}

\subsection{Chemicals and Reagents}

Polyethylene glycol 400 (PEG 400) and heparin sodium were purchased from Sigma-Aldrich (St. Louis, MO, USA). Pentobarbital sodium was obtained from SCI Phar-matech (Toayuan, Taiwan). S. chinensis was purchased from Kaiser Pharmaceutical Co., Ltd. (Tainan, Taiwan). Methanol, ethyl acetate and formic acid were obtained from E. Merck (Darmstadt, Germany). Triply deionized water (Millipore, Bedford, MA, USA) was used for all preparations.

\subsection{Experimental Animals}

All experimental protocols involving animals were reviewed and approved by the Institutional Animal Care and Use Committee (IACUC number: 1060813) of National Yang-Ming University. Male Sprague-Dawley rats were obtained from the Laboratory Animal Center of the National Yang-Ming University, Taipei, Taiwan. The animals had free access to food (laboratory rodent diet 5P14, PMI Feeds, Richmond, IN) and water. Six Sprague-Dawley rats (220-240 g) were anesthetized with pentobarbital (50 mg/kg, i.p.) for cannulation. Surgical sites were shaved and disinfected with $70 \%$ ethanol solution, and a polyethylene tube (PE50) was implanted into the right jugular vein for collecting blood samples. The cannula were exteriorized and fixed in the dorsal region of the neck. Patency of the tube was maintained by flushing with heparinized saline $(20 \mathrm{IU} / \mathrm{mL})$. Rats were allowed to recover $24 \mathrm{~h}$ prior to drug administration. Schizandrin was dissolved in 10\%DMSO and triply deionized water and administered by gastric gavage at a dose of $10 \mathrm{mg} / \mathrm{kg}$. Schizandrin was dissolved in $10 \%$ ethanoland triply deionized water and administered by intravenous injection at a dose of $10 \mathrm{mg} / \mathrm{kg}$. The S. chinensis pharmaceutical product was dissolved in triply deionized water and administered by gastric gavage at a dose of $3 \mathrm{~g} / \mathrm{kg}$ and $10 \mathrm{~g} / \mathrm{kg}$ (equivalent to $5.2 \mathrm{mg} / \mathrm{kg}$ and $17.3 \mathrm{mg} / \mathrm{kg}$ schizandrin). The gavage administration of $S$. chinensis volume was $3 \mathrm{~mL}$. A $200 \mu \mathrm{L}$ blood sample was withdrawn from the right jugular vein at the carotid artery into a heparin-rinsed vial at 5, 15, 30, 45, 60, 90, 120, 150, 180, 240, 360 
and $480 \mathrm{~min}$. Blood samples were centrifuged at $6000 \times \mathrm{g}$ for $10 \mathrm{~min}$ at $4{ }^{\circ} \mathrm{C}$. The biological samples were stored at $-20^{\circ} \mathrm{C}$ before analysis.

\subsection{Sample Preparation}

Each blood sample $(50 \mu \mathrm{L})$ was mixed with $1 \mathrm{~mL}$ of ethyl acetate and vortexed for $5 \mathrm{~min}$. The mixture was centrifuged at $16,000 \times g$ for $10 \mathrm{~min}$ at $4{ }^{\circ} \mathrm{C}$. The supernatant $(1 \mathrm{~mL})$ was transferred to an Eppendorf vial and dried at $40^{\circ} \mathrm{C}$ in a centrifugation evaporator. The dried sample was reconstituted in $190 \mu \mathrm{L}$ of methanol and IS solution (methyl yellow, $5 \mathrm{ng} / \mathrm{mL}$ in methanol) and filtered through a $0.22 \mu \mathrm{m}$ filter. Finally, the filtrate $(10 \mu \mathrm{L})$ was applied to the UPLC-MS/MS system for analysis.

\subsection{LC-MS/MS}

The LC-MS/MS analysis was performed using a Waters Acquity UPLC ${ }^{\mathrm{TM}}$ system (Waters Co., Manchester, UK) consisting of binary solvent manager, an automatic liquid chromatographic sampler and a Waters $\mathrm{Xevo}^{\mathrm{TM}}$ tandem quadrupole mass spectrometry equipped with an electrospray ionization (ESI) source. The chromatography was performed on a Purospher ${ }^{\circledR}$ STAR RP-18 endcapped (100 mm $\times 2.1 \mathrm{~mm}, 2 \mu \mathrm{m}$, Merck KGaA, Darmstadt, Germany) analytical column and maintained at $40{ }^{\circ} \mathrm{C}$ in a column oven. The mobile phase consisted of $0.1 \%$ formic acid-methanol $(15: 85, v / v)$, and the flow rate was set at $0.2 \mathrm{~mL} / \mathrm{min}$. The injection volume was $10 \mu \mathrm{L}$. The positive ion mode with a multiple reaction monitor (MRM) was used for UPLC-MS/MS analysis. The following precursor-to-product ion transitions were used: $m / z 433.22 \rightarrow 415.19$ for schizandrin and $m / z 226.26 \rightarrow 76.91$ for methyl yellow (internal standard, IS).The instrument parameters were optimized as follows: capillary voltage, $3.2 \mathrm{kV}$; desolvation gas, nitrogen; desolvation temperature, $400{ }^{\circ} \mathrm{C}$; desolvation gas flow rate, $800 \mathrm{~L} / \mathrm{h}$; cone voltage, $18 \mathrm{~V}$; collision energy, $12 \mathrm{~V}$ and source temperature, $150^{\circ} \mathrm{C}$. MassLynx 4.1 software (Waters Corporation, Milford, MA, USA) was used for data processing.

\subsection{Method Validation}

Method validation was performed based on the US FDA guidelines for bioanalytical method validation (Guidance for Industry: Bioanalytical Method Validation, 2001), which contains methods for the lower limit of quantification, matrix effect, recovery, accuracy and precision, calibration curve and stability.

\subsubsection{Accuracy, Precision and Linearity}

Linearity was determined in the range of $5-500 \mathrm{ng} / \mathrm{mL}$. The calibration curve was created from the ratio of the peak areas of schizandrin and methyl yellow to the nominal concentration of schizandrin. The correlation coefficient $\left(\mathrm{r}^{2}\right)$ value of all calibration curves was greater than 0.995 . The accuracy (bias \%) was calculated from the mean value of the observed concentration $\left(\mathrm{C}_{\mathrm{obs}}\right)$ and nominal concentration $\left(C_{\text {nom }}\right)$ using the relationship accuracy (bias $\left.\%\right)=\left[\left(C_{o b s}-C_{n o m}\right) / C_{n o m}\right] \times 100$. The relative standard deviation (RSD) was calculated from the observed concentrations as precision $($ RSD $\%)=$ [standard deviation $\left.(\mathrm{SD}) / \mathrm{C}_{\mathrm{obs}}\right] \times 100$.Intra-day and inter-day variations of the method in rat samples were less than $\pm 15 \%( \pm 20 \%$ at the lower limit of detection) for all analytes. The limit of quantification (LOQ) was defined as the lowest concentration of the linear range, and the limit of detection (LOD) was defined as the concentration of analyte giving a signal-to-noise ratio $(\mathrm{S} / \mathrm{N})$ of 3 .

\subsubsection{Stability}

Stability was evaluated under four conditions: short-term stability kept at room temperature for $6 \mathrm{~h}$; post-preparative stability kept in the autosampler at $8{ }^{\circ} \mathrm{C}$ for $6 \mathrm{~h}$; long-term stability kept at $-80^{\circ} \mathrm{C}$ for 1 month; and freeze-thaw stability: three samples were frozen and stored at $-20^{\circ} \mathrm{C}$ for $24 \mathrm{~h}$ and then thawed at room temperature. After repeating this cycle three times, the samples were analyzed by UHPLC-MS/MS. 


\subsubsection{Recovery and Matrix Effect}

The recovery and matrix effects of schizandrin in various blood samples were assessed at three different concentrations $(5,50$, and $500 \mathrm{ng} / \mathrm{mL}$ ). The methyl yellow (IS) concentration was $5 \mathrm{ng} / \mathrm{mL}$ in rat plasma. Three sets of extraction methods were prepared to evaluate recovery and matrix effects in the quantitative bioanalytical method:

Set 1. Standard schizandrin solutions. The samples were prepared by placing $10 \mu \mathrm{L}$ of the appropriate concentrations of schizandrin and methyl yellow and $180 \mu \mathrm{L}$ of methanol into $1.5 \mathrm{~mL}$ Eppendorf tubes. After mixing, the solutions were transferred into HPLC vials, and $10 \mu \mathrm{L}$ was injected into the LC-MS/MS system.

Set 2. Schizandrin solutions spiked after extraction. The samples were prepared by placing $50 \mu \mathrm{L}$ of blank plasma in $1.5 \mathrm{~mL}$ Eppendorf tubes, followed by the addition of $500 \mu \mathrm{L}$ of ethyl acetate for a liquid-liquid extract. The samples were mixed $(5 \mathrm{~min})$ and centrifuged $\left(15,000 \mathrm{rpm}\right.$ for $10 \mathrm{~min}$ at $\left.4^{\circ} \mathrm{C}\right)$ twice. The supernatant was collected in Eppendorf tubes and evaporated to dryness at $50{ }^{\circ} \mathrm{C}$ for $30 \mathrm{~min}$ and then reconstituted with $10 \mu \mathrm{L}$ of the appropriate concentration of schizandrin and internal standard and $180 \mu \mathrm{L}$ of methanol. After mixing, the solutions were transferred to HPLC vials, and $10 \mu \mathrm{L}$ was injected into the LC system for analysis. In set 2, schizandrin was spiked post-extraction into different plasma samples, whereas in set 3, schizandrin was spiked into different plasma samples pre-extraction.

Set 3. Schizandrin solutions spiked before extraction. The samples were prepared by placing $50 \mu \mathrm{L}$ of blank plasma in $1.5 \mathrm{~mL}$ Eppendorf tubes, to which $10 \mu \mathrm{L}$ of appropriate concentrations of schizandrin were added before extraction, followed by the addition of $500 \mu \mathrm{L}$ of ethyl acetate for liquid-liquid extraction. After centrifugation (15,000 rpm for $10 \mathrm{~min}$ at $\left.4^{\circ} \mathrm{C}\right)$, this step was repeated twice. The supernatant was collected in Eppendorf tubes and evaporated to dryness at $50^{\circ} \mathrm{C}$ for $30 \mathrm{~min}$. Samples were reconstituted with $190 \mu \mathrm{L}$ of methanol and $10 \mu \mathrm{L}$ of internal standard. After mixing, the solutions were transferred to HPLC vials, and $10 \mu \mathrm{L}$ was injected into the LC system for analysis. Recovery (\%) and matrix effects (\%) were calculated by using the peak area of set $2 /$ set 1 and set $3 /$ set 2 , respectively.

\subsection{Pharmacokinetic Data Analysis}

Pharmacokinetic calculations were performed on each individual set of data using the pharmacokinetic software WinNonlin Standard Edition, version 1.1 (Scientific Consulting Inc., Apex, NC, USA) by noncompartmental methods for intravenous and oral administration. The results were analyzed using Student's t-test and the SigmaPlot program (version 13). All data are presented as the mean \pm standard deviation (SD).

\section{Conclusions}

A reliable and sensitive UHPLC-MS/MS method for the analysis of schizandrin in biological samples has been successfully validated and developed. This method had sensitivity, precision, accuracy, selectivity, recovery and stability for the determination of schizandrin in biological samples. In addition, this method was successfully applied in a pharmacokinetic study of schizandrin in freely moving rats after oral administration of pharmaceutical products of $S$. chinensis.

Acknowledgments: This study was supported in part by research grants from the National Science Council Taiwan (MOST106-2113-M-010-002) and the NYMU-FEMH Joint Research Program (106DN22).

Author Contributions: The authors contributed to this work as follows: C.-L.L. and Y.-Y.C. performed the study, analyzed the data and prepared the manuscript. C.-H.H. assisted in editing the manuscript. T.-H.T. designed the experiments and edited the paper and secured funding.

Conflicts of Interest: The authors declare no conflicts of interest. 


\section{References}

1. Lai, Q.; Wei, J.; Mahmoodurrahman, M.; Zhang, C.; Quan, S.; Li, T.; Yu, Y. Pharmacokinetic and nephroprotective benefits of using Schisandra chinensis extracts in a cyclosporine A-based immune-suppressive regime. Drug Des. Dev. Ther. 2015, 9, 4997-5018.

2. Liu, K.T.; Cresteil, T.; Columelli, S.; Lesca, P. Pharmacological properties of dibenzo[a,c]cyclooctene derivatives isolated from Fructus Schizandrae chinensis II. Induction of phenobarbital-like hepatic monooxygen ases. Chem.-Biol. Interact. 1982, 39, 315-330. [CrossRef]

3. Chen, X.; Huang, Y.; Feng, J.; Jiang, X.F.; Xiao, W.F.; Chen, X.X. Antioxidant and anti-inflammatory effects of Schisandra and Paeonia extracts in the treatment of asthma. Exp. Ther. Med. 2014, 8, 1479-1483. [CrossRef] [PubMed]

4. Kim, H.; Ahn, Y.T.; Kim, Y.S.; Cho, S.I.; An, W.G. Antiasthmatic effects of schizandrae fructus extract in mice with asthma. Pharmacogn. Mag. 2014, 10, S80-S85. [PubMed]

5. Lee, K.P.; Kang, S.; Park, S.J.; Kim, J.M.; Lee, J.M.; Lee, A.Y.; Chung, H.Y.; Choi, Y.W.; Lee, Y.G.; Im, D.S. Anti-allergic effect of alpha-cubebenoate isolated from Schisandra chinensis using in vivo and in vitro experiments. J. Ethnopharmacol. 2015, 173, 361-369. [CrossRef] [PubMed]

6. Niu, J.; Xu, G.; Jiang, S.; Li, H.; Yuan, G. In Vitro Antioxidant activities and anti-diabetic effect of a polysaccharide from Schisandra sphenanthera in rats with type 2 diabetes. Int. J. Biol. Macromol. 2017, 94, 154-160. [CrossRef] [PubMed]

7. Zhang, C.; Zhao, X.; Mao, X.; Liu, A.; Liu, Z.; Li, X.; Bi, K.; Jia, Y. Pharmacological evaluation of sedative and hypnotic effects of schizandrin through the modification of pentobarbital-induced sleep behaviors in mice. Eur. J. Pharmacol. 2014, 744, 157-163. [CrossRef] [PubMed]

8. Zhu, H.; Zhang, L.; Wang, G.; He, Z.; Zhao, Y.; Xu, Y.; Gao, Y. Sedative and hypnotic effects of supercritical carbon dioxide fluid extraction from Schisandra chinensis in mice. J. Food Drug Anal. 2016, 24, 831-838. [CrossRef] [PubMed]

9. Opletal, L.; Sovova, H.; Bartlova, M. Dibenzo[a,c]cyclooctadiene lignans of the genus Schisandra: Importance, isolation and determination. J. Chromatogr. B 2004, 812, 357-371. [CrossRef]

10. Huang, H.; Shen, Z.; Geng, Q.; Wu, Z.; Shi, P.; Miao, X. Protective effect of Schisandra chinensis bee pollen extract on liver and kidney injury induced by cisplatin in rats. Biomed. Pharmacother. 2017, 95, 1765-1776. [CrossRef] [PubMed]

11. Zhang, R.; Wang, Y.; Zhu, D.; Dong, F.; Chen, X. The protective effect of North Schisandra Lignans on vascular endothelial cell oxidation injuries. Technol. Health Care 2016, 24, S651-657. [CrossRef] [PubMed]

12. Liu, K.T.; Cresteil, T.; Le Provost, E.; Lesca, P. Specific evidence that schizandrins induce a phenobarbital-like cytochrome P-450 form separated from rat liver. Biochem. Biophys. Res. Commun. 1981, 103, 1131-1137. [CrossRef]

13. Jiang, Y.M.; Wang, Y.; Tan, H.S.; Yu, T.; Fan, X.M.; Chen, P.; Zeng, H.; Huang, M.; Bi, H.C. Schisandrol $B$ protects against acetaminophen-induced acute hepatotoxicity in mice via activation of the NRF2/ARE signaling pathway. Acta Pharmacol. Sin. 2016, 37, 382-389. [CrossRef] [PubMed]

14. Yang, X.W.; Hattori, M.; Namba, T.; Chen, D.F.; Xu, G.J. Anti-lipid peroxidative effect of an extract of the stems of Kadsura heteroclita and its major constituent, kadsurin, in mice. Chem. Pharm. Bull. 1992, 40, 406-409. [CrossRef] [PubMed]

15. Yang, G.Y.; Wang, R.R.; Mu, H.X.; Li, Y.K.; Xiao, W.L.; Yang, L.M.; Pu, J.X.; Zheng, Y.T.; Sun, H.D. Neolignans from Schisandra wilsoniana and their anti-human immunodeficiency virus-1 activities. Chem. Pharm. Bull. 2011, 59, 1344-1347. [CrossRef] [PubMed]

16. Xu, L.; Grandi, N.; Del Vecchio, C.; Mandas, D.; Corona, A.; Piano, D.; Esposito, F.; Parolin, C.; Tramontano, E. From the traditional Chinese medicine plant Schisandra chinensis new scaffolds effective on HIV-1 reverse transcriptase resistant to non-nucleoside inhibitors. J. Microbiol. 2015, 53, 288-293. [CrossRef] [PubMed]

17. Poornima, B.; Siva, B.; Shankaraiah, G.; Venkanna, A.; Nayak, V.L.; Ramakrishna, S.; Venkat Rao, C.; Babu, K.S. Novel sesquiterpenes from Schisandra grandiflora: Isolation, cytotoxic activity and synthesis of their triazole derivatives using "click" reaction. Eur. J. Med. Chem. 2015, 92, 449-458. [CrossRef] [PubMed]

18. Venkanna, A.; Siva, B.; Poornima, B.; Vadaparthi, P.R.; Prasad, K.R.; Reddy, K.A.; Reddy, G.B.; Babu, K.S. Phytochemical investigation of sesquiterpenes from the fruits of Schisandra chinensis and their cytotoxic activity. Fitoterapia 2014, 95, 102-108. [CrossRef] [PubMed]

19. Li, X.N.; Cui, H.; Song, Y.Q.; Liang, Y.Z.; Chau, F.T. Analysis of volatile fractions of Schisandra chinensis (Turcz.) Baill. using GC-MS and chemometric resolution. Phytochem. Anal. 2003, 14, 23-33. [CrossRef] [PubMed] 
20. Ono, H.; Matsuzaki, Y.; Wakui, Y.; Takeda, S.; Ikeya, Y.; Amagaya, S.; Maruno, M. Determination of schizandrin in human plasma by gas chromatography-mass spectrometry. J. Chromatogr. B Biomed. Sci. Appl. 1995, 674, 293-297. [CrossRef]

21. Matsuzaki, Y.; Ishibashi, E.; Koguchi, S.; Wakui, Y.; Takeda, S.; Aburada, M.; Oyama, T. Determination of gomisin A (TJN-101) and its metabolite in rat serum by gas chromatography-mass spectrometry. Yakugaku Zasshi 1991, 111, 617-620. [CrossRef] [PubMed]

22. Lee, K.Y.; Shin, Y.J.; Kim, D.H.; Park, J.H.; Kim, S.H.; Han, S.B.; Sung, S.H. Micelle-mediated extraction of dibenzocyclooctadiene lignans from Schisandra chinensis with analysis by high-performance liquid chromatography. J. Chromatogr. Sci. 2014, 52, 745-750. [CrossRef] [PubMed]

23. Shi, J.; Xu, X.; Li, X.; Liu, C.; Shao, M.; Zhang, H.; Wang, Z.; Zhang, H.; Huan, Y. Determination of lignans in Wuweizi by using magnetic bar microextraction and HPLC. J. Sep. Sci. 2013, 36, 3527-3533. [CrossRef] [PubMed]

24. Sun, D.; Li, Q.; Li, H.; Li, Y.; Piao, Z. Quantitative analysis of six lignans in fruits with different colours of Schisandra chinensis by HPLC. Nat. Prod. Res. 2014, 28, 581-585. [CrossRef] [PubMed]

25. Wang, K.; Song, W.; Tong, Y. Identification of Schisardra by TLC-densitometry. Zhongguo Zhong Yao Za Zhi 1991, 16, 70-71. [PubMed]

26. Wang, K.; Tong, Y.Y.; Song, W.Z. Determination of the active ingredients in Chinese drug wuweizi (Schisandra chinensis) by TLC-densitometry. Yao Xue Xue Bao 1990, 25, 49-53. [PubMed]

27. He, X.G.; Lian, L.Z.; Lin, L.Z. Analysis of lignan constituents from Schisandra chinensis by liquid chromatography-electrospray mass spectrometry. J. Chromatogr. A 1997, 757, 81-87. [CrossRef]

28. Zhu, L.; Li, B.; Liu, X.; Huang, G.; Meng, X. Purification of six lignans from the stems of Schisandra chinensis by using high-speed counter-current chromatography combined with preparative high-performance liquid chromatography. Food Chem. 2015, 186, 146-152. [CrossRef] [PubMed]

29. Zhu, L.; Li, B.; Liu, X.; Meng, X. Purification of two triterpenoids from Schisandra chinensis by macroporous resin combined with high-speed counter-current chromatography. J. Chromatogr. Sci. 2014, 52, 1082-1088. [CrossRef] [PubMed]

30. Zhan, S.; Guo, W.; Shao, Q.; Fan, X.; Li, Z.; Cheng, Y. A pharmacokinetic and pharmacodynamic study of drug-drug interaction between ginsenoside Rg1, ginsenoside Rb1 and schizandrin after intravenous administration to rats. J. Ethnopharmacol. 2014, 152, 333-339. [CrossRef] [PubMed]

31. McDowall, R.D. Sample preparation for biomedical analysis. J. Chromatogr. 1989, 11, 3-58. [CrossRef]

32. Zhan, S.; Shao, Q.; Fan, X.; Li, Z. Development of a sensitive LC-MS/MS method for simultaneous quantification of eleven constituents in rat serum and its application to a pharmacokinetic study of a Chinese medicine Shengmai injection. Biomed. Chromatogr. 2015, 29, 275-284. [CrossRef] [PubMed]

33. Diehl, K.H.; Hull, R.; Morton, D.; Pfister, R.; Rabemampianina, Y.; Smith, D.; Vidal, J.M.; van de Vorstenbosch, C.; European Federation of Pharmaceutical Industries Association; European Centre for the Validation of Alternative Methods. A Good Practice Guide to the Administration of Substances and Removal of Blood, Including Routes and Volumes. J. Appl. Toxicol. 2001, 21, 15-23. [CrossRef] [PubMed]

34. Wang, B.L.; Hu, J.P.; Tan, W.; Sheng, L.; Chen, H.; Li, Y. Simultaneous quantification of four active schisandra lignans from a traditional Chinese medicine Schisandra chinensis (Wuweizi) in rat plasma using liquid chromatography/mass spectrometry. J. Chromatogr. B Anal. Technol. Biomed. Life Sci. 2008, 865, 114-120. [CrossRef] [PubMed]

35. Feary, D.J.; Mama, K.R.; Wagner, A.E.; Thomasy, S. Influence of general anesthesia on pharmacokinetics of intravenous lidocaine infusion in horses. Am. J. Vet. Res. 2005, 66, 574-580. [CrossRef] [PubMed]

36. Xu, M.; Wang, G.; Xie, H.; Wang, R.; Wang, W.; Li, X.; Li, H.; Zhu, D.; Yue, L. Determination of schizandrin in rat plasma by high-performance liquid chromatography-mass spectrometry and its application in rat pharmacokinetic studies. J. Chromatogr. B Anal. Technol. Biomed. Life Sci. 2005, 828, 55-61. [CrossRef] [PubMed]

37. Craik, D.J.; Fairlie, D.P.; Liras, S.; Price, D. The future of peptide-based drugs. Chem. Biol. Drug Des. 2013, 81, 136-147. [CrossRef] [PubMed]

Sample Availability: Samples of the compounds schizandrine is available from the authors. 